九州大学学術情報リポジトリ

Kyushu University Institutional Repository

\title{
Numerical Analysis of Humidification Dehumidification Desalination System
}

Bakthavatchalam, Balaji

Department of Mechanical Engineering, Universiti Teknologi Petronas

Rajasekar K.

Department of Mechanical Engineering, IIITDM Kanchipuram

Habib, Khairul

Department of Mechanical Engineering, Universiti Teknologi Petronas

R. Saidur

Research Centre for Nano-materials and Energy Technology (RCNMET), School of Science and Technology, Sunway University

他

https://doi.org/10.5109/2320996

出版情報 : Evergreen. 6 (1)，pp.9-17，2019-03. 九州大学グリーンアジア国際リーダー教育センター バージョン：

権利関係 : 


\title{
Numerical Analysis of Humidification Dehumidification Desalination System
}

\author{
Balaji Bakthavatchalam ${ }^{1,{ }^{*}}$,Rajasekar K. ${ }^{2}$, Khairul Habib ${ }^{3}$, \\ R. Saidur ${ }^{4}$, Firdaus Basrawi ${ }^{5}$ \\ ${ }^{1,3}$ Department of Mechanical Engineering, Universiti Teknologi Petronas, Seri Iskandar, Malaysia \\ ${ }^{2}$ Department of Mechanical Engineering, IIITDM Kanchipuram, Chennai, India \\ ${ }^{4}$ Research Centre for Nano-materials and Energy Technology (RCNMET), School of Science and \\ Technology, Sunway University, Selangor, Malaysia \\ ${ }^{5}$ Department of Mechanical Engineering, Universiti Malaysia Pahang, Pahang, Malaysia \\ *Email: balaji_17004028@utp.edu.my
}

(Received August 9, 2018; accepted January 10, 2019).

\begin{abstract}
Increasing population combined with pollution of water bodies makes human being on this earth fully dependent on purified or desalinated water Keeping in mind the end goal to take care of the demand for consumable water, desalination systems of different kind have been proposed by many industrial establishments and research groups. Among the known water purification system Humidification Dehumidification (HDH) has become popular due to its simple operation, economic viability, absence of skilled labor and dependence on green and low grade energy to power the system. The theoretical analysis has been carried out using a simulation code in ' $\mathrm{C}$ ' language to study the performance and quantity of output at various operating conditions. Results demonstrate that with increment in the mass flow rate of water and air, the effect of productivity on desalinated water increases and decreases respectively. In addition, the freshwater output increases with decrease in the heat input which is favorable for the enhancement of desalination efficiency.
\end{abstract}

Keywords: Humidification, Dehumidification, Desalinated Water, Performance.

\section{Introduction}

Humans, plants and animals all need fresh water to survive. There are numerous locales of the world that are honored with a plenitude of fresh water. Yet, thickly populated zones, developing quick industrialization, are encountering more unpleasant pressure, particularly when they are situated in dry areas. A water poll demonstrates that in excess of a billion people having a place with a lower wage bunch don't approach safe drinking water with the world over. This kind of ill-fated circumstances enforces governmental and non-governmental bodies to help create a feasible solution to provide fresh water to all communities throughout the year. An implementable arrangement is really beneficial just in the event that it is versatile and can achieve countless (say, a million or more). For such versatility, hypothetical examination of HDH can be an answer to handle a variety of contaminants in the water to be dealt with.

Many theoretical and experimental investigation has been performed on HDH desalination systems due to its remarkable advantages. Zubair et al. [1] used two HDH cycles to create an empirical and experimental model. The model utilizing Open air water cycle (OAOW) resulted in great accord with the altered Closed water open air cycle (CWOA) amidst a most extreme rate deviation of 5\%. Dahiru et al. [2] developed a HDH desalination framework controlled by a heat pump. With mass and energy balance equations, they also proposed a numerical model using closed air with open heating and an altered cycle with air heated. They acquired the most extreme GOR 8.88 at $80 \%$ viability for cycles with heated air and water. Soufari et al. [3] built up a program to advance the execution of the HDH framework, he worked in that to limit specific energy consumption, amplification of profitability, and boost of condenser heat recuperation and inferred that the ratio of mass flow rate of water and air is the best parameter and furthermore humidifier channel water temperature will also be a vital parameter. Previous research by Gang et al. [4] demonstrated that the GOR (Gained Output Ratio) of the HDH desalination systems increases with increase in the operating temperature especially after $340 \mathrm{~K}$. He et al. [5] obtained a maximum GOR of 2.44 at a pressure of $0.15 \mathrm{MPa}$ due to the modification of heat capacity ratio of the dehumidifier in their simulation. In their another work they also investigated the effect of coupling a heat pump with $\mathrm{HDH}$ desalination system where they achieved a GOR and yield of 5.4 and $106.53 \mathrm{Kgh}^{-1}$ 
respectively and concluded that less temperature difference and higher effectiveness value of the condenser is responsible for more water production and thermal efficiency for both humidifier and dehumidifier [6]. Ahmed et al. [7] have analyzed that the GOR of the HDH system with a closed-air closed desiccator decreases with the increase of the humidifier enthalpy which reduces the heat and the potential mass transfer that influences the evaporation rate of the humidifier which led to a decrease in the production of fresh water. Nabil et al. [8] studied the effect of rate of flow and temperature of geothermal water, where productivity and GOR are $104 \mathrm{~L} / \mathrm{m} 2$ and 1.2 respectively in their proposed HDH desalination system driven by solar energy. A recent study by Shafii et al. [9] confirmed that with an increase in volumetric flow rate and relative air humidity in the dehumidification section GOR 2.08 was obtained, and, on the other hand, an increase in ambient temperature caused a decrease in the GOR system. Based on the mathematical model proposed by $\mathrm{He}$ and $\mathrm{Xu}$ [10], the more efficiency of the humidifier and the high inlet temperature from the sea water of the humidifier increased the GOR value by approximately $37.02 \%$. Said et al. [11] compiled a mathematical model for studying the performance of the HDH desalination system integrated with a heat pump enclosed in a humidifier with direct contact. They reported that increase in the temperature of the upper sea water and fresh water increased the HDH GOR system from 0.54 to 0.73 . Hadi et al. [12] optimized the GOR value and water production performance by combining an absorption heat pump in the HDH desalination system. They produced a maximum of $0.647 \mathrm{~kg} / \mathrm{s}$ of fresh water, including GOR and EGOR (Exergy-based GOR) 9.02 and 3.04. Jung-Hong et al. [13] used a Photo voltaic driven HDH system (PVHDH) working under free or forced convection mode, ensured that desalination of brackish water is also technically and economically feasible comparing with traditional water treatment plants. The analysts in past works typically centered around macroscopic and thermodynamic modelling utilizing many external resources like heat pump, desiccant layers, heat exchangers etc. which contributes to more cost and maintenance. Here, in this study, we developed a modified mathematical model (with $\mathrm{C}$ language) that uses direct natural sources of energy to predict the parameters responsible for increasing the productivity of fresh water in the HDH desalination system.

\subsection{Desalination}

Desalination advancements can evacuate all contaminants including every single broke down particle, microorganisms and different toxins. The accompanying are desalination innovations designed by technocrats:

- Solar still

- $\quad$ Nano Filtration (NF)
- $\quad$ Freezing desalination

- Geothermal desalination

- $\quad$ Forward osmosis (FO)

- Wave-powered desalination

- $\quad$ Ion exchange

The difficulties in executing these advances are, nonetheless, to make them ease, to give them at a network scale and to make them moderately support free (or if nothing else viable by non-specialized workers) [4]. Desalination is, and will be later on, a suitable and even vital method for producing freshwater from water of moderately low quality. In this venture, we put forth the defense for desalination as one of the real instruments for meeting the pure water needs of a developing planet.

\subsection{Working of an HDH System}

It is a well-known fact that most of the researches in Humidification and Dehumidification systems have contributed to the development of different sizes of desalination frames according to the requirements and prerequisites. The activity of the structure can be illustrated in Fig. 1. Naturally, sea water gets desalinated by the circulation of rain water especially with the rays of sunlight. In the rain cycle, the sea is heated and moistens the air that holds the gas. Humid air rises and forms a fog. Finally, the clouds "drain" the rain. Moisturizing and drying the desalting solution using the $\mathrm{HDH}$ cycle is the most encouraging permanent improvement in desalination. When the flow of air contacts the brine, the HDH procedure depends on how the air is mixed with a large amount of water vapor. A certain amount of steam is released in the air that induces cooling and then the steam condensation occurs in the air due to the contact of moist air with the cooled surface which in turn helps to recover the purified water.

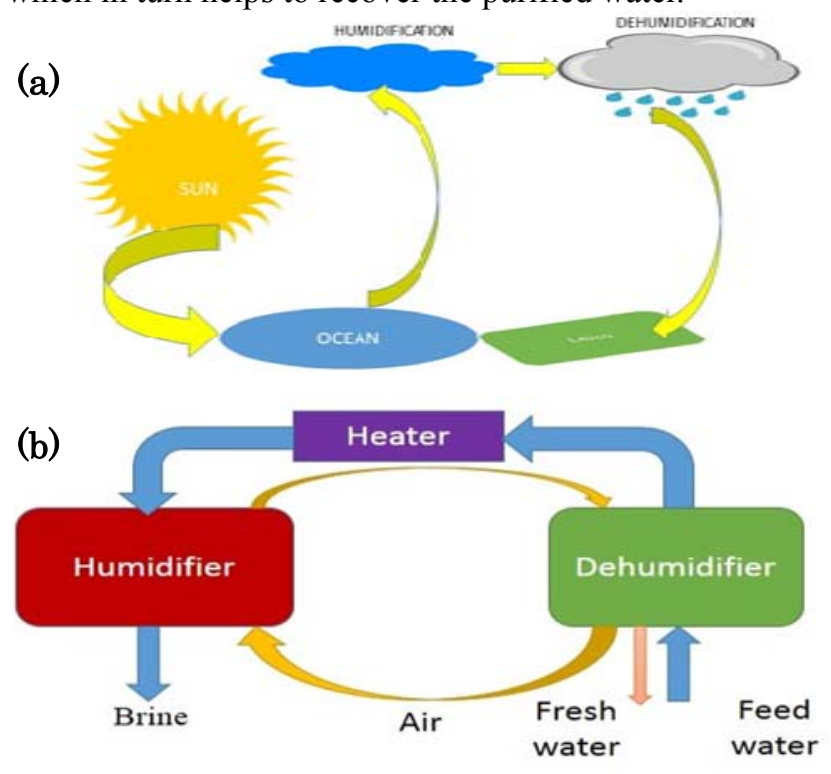

Fig. 1: (a) Rain Cycle (b) Simple HDH Cycle 


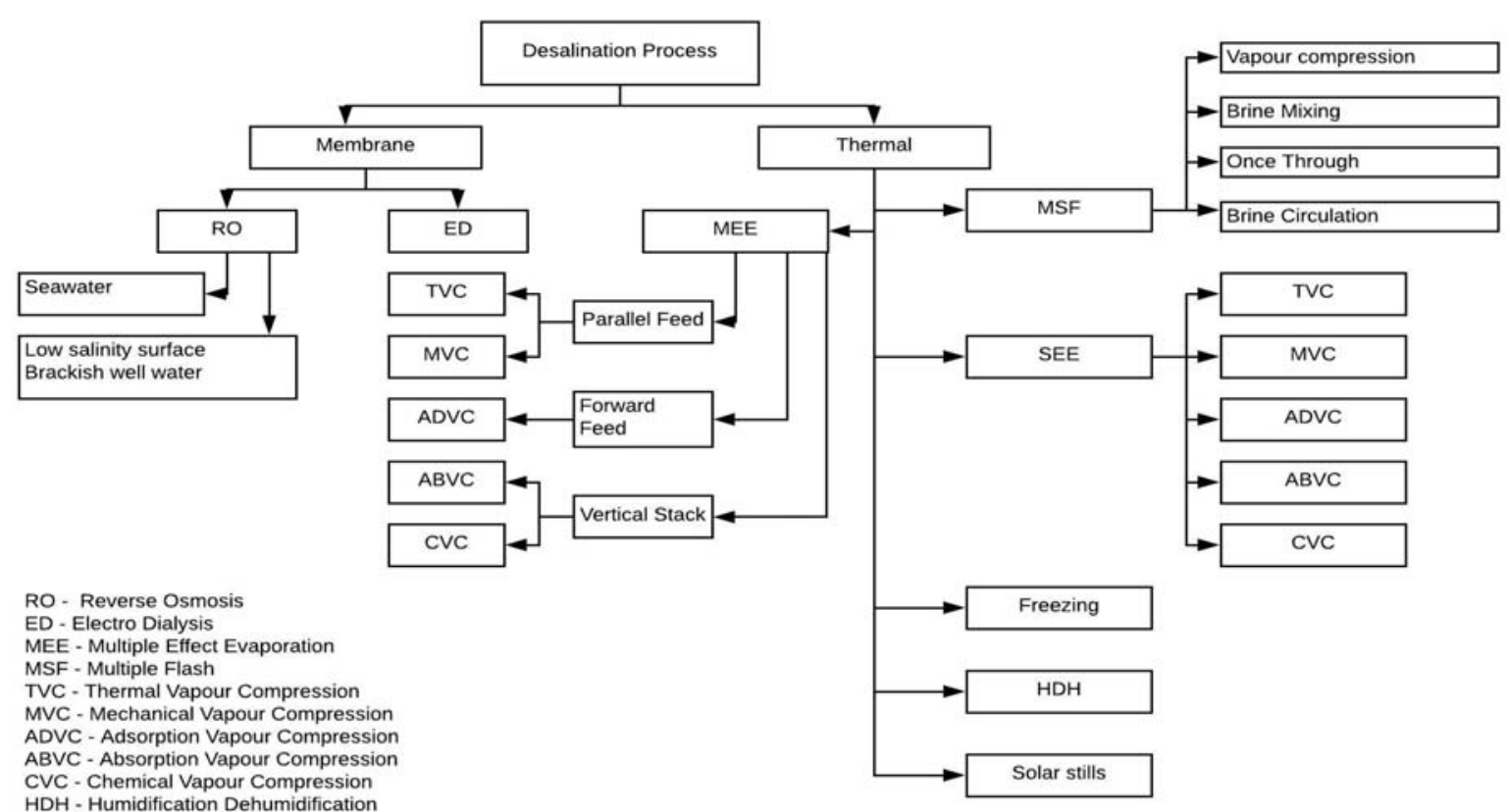

Fig. 2: Types of desalination

\section{Different types of Desalination}

It is estimated that $0.3 \%$ of the global carbon emission is emitted from the present desalination technology since it is dependent on the electricity produced from traditional fossil fuels, even though it contributes only $0.34 \%$ of the global fresh water supply. By 2050 , this $0.34 \%$ contribution will be enhanced to at least $10 \%$ that will lead to $14 \%$ of global carbon emission. Therefore, it is necessary to search for an alternative desalination technology like $\mathrm{HDH}$ desalination system which can work on renewable energy [14].

\section{Methodology}

A simulation code was developed in the ' $\mathrm{C}$ ' language for the $\mathrm{HDH}$ desalination system for analyzing its performance, the simulation code includes general input characteristics such as heating power, sea water salinity, temperature of water inlet, air inlet temperature, water temperature for spraying, mass flow rate of sea water and air. The principles of thermodynamics are used to calculate the thermophysical properties required for air and seawater likewise, the psychometric relationships available in the literature give specific humidity, relative humidity, steam pressure and enthalpy. The simulation code provides output information on the various input parameters, the effects of the input parameters, the fluid conditions such as the liquid temperature, the relative humidity, the specific humidity and air at each stage.

\subsection{Assumptions made in the study}

- The system operates at steady state conditions.

- Humidifiers and dehumidifiers do not cause heat loss in the environment.

- Pumping power and blower power are negligible compared to the heater's power consumption

- The temperature of humidified air coming out of the humidifier is equivalent to the spray water temperature.

- $\quad$ The flow is one directional.

Despite the kind of humidification dehumidification framework, the accompanying numerical model is utilized to assess the essential characteristics needed for the examination of the desalination unit.

\subsection{Physical properties of air}

The accompanying equations are expected to examine the fundamental properties of air [15].

Specific humidity

$$
\omega=0.622 \frac{p_{v s}}{\left(p_{t}-p_{v s}\right)}
$$

Saturated vapor

pressure

$$
p_{v s}=\exp \left(23.5771-\frac{4042.9}{(T-37.58)}\right.
$$

Relative humidity

$$
\phi=\frac{p_{v s}}{p}
$$

Enthalpy of moist air

$$
\begin{aligned}
& h=h_{a}+\omega h_{v} \\
& h=c_{p a} T+\omega(2501+1.9 T)
\end{aligned}
$$




\subsection{Physical model of Humidifier and Dehumidifier}

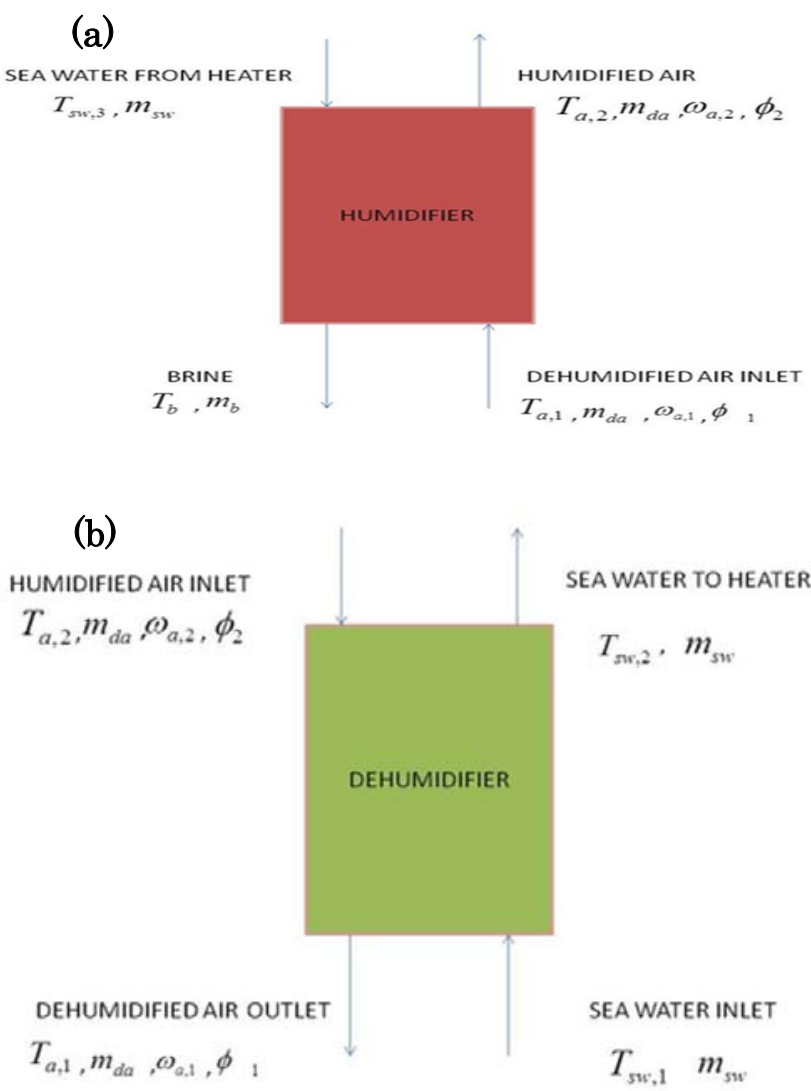

Fig. 3: (a) Physical model of Humidifier (b) Physical model of Dehumidifier

The humidifier acts as an evaporator in the $\mathrm{HDH}$ system when the air flows inside the humidifier, since the water spray will mix with the air flow inside the humidifier, because of this some water will evaporate and be carried out by the air flow, the amount of water evaporation is based on the temperature of the sprayed water temperature and mass flow rate of air, and thus negligible external energy is needed. At a certain temperature of the liquid, partial pressure becomes equal to the saturation pressure where the formation of saturated vapor occurs. Dehumidifiers acts as condenser in HDH Desalination systems to dehumidify the moisture air coming out of the humidifier to produce the fresh water by using the sea water. Cooling water flows in the coil of the heat exchanger, and the wind flows through the bearing of the costal ring in the condenser cabinet.

\subsection{Physical model of heater and Closed Air Open Water Cycle}

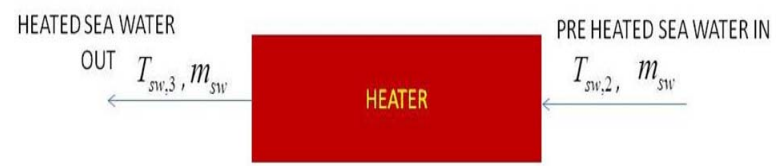

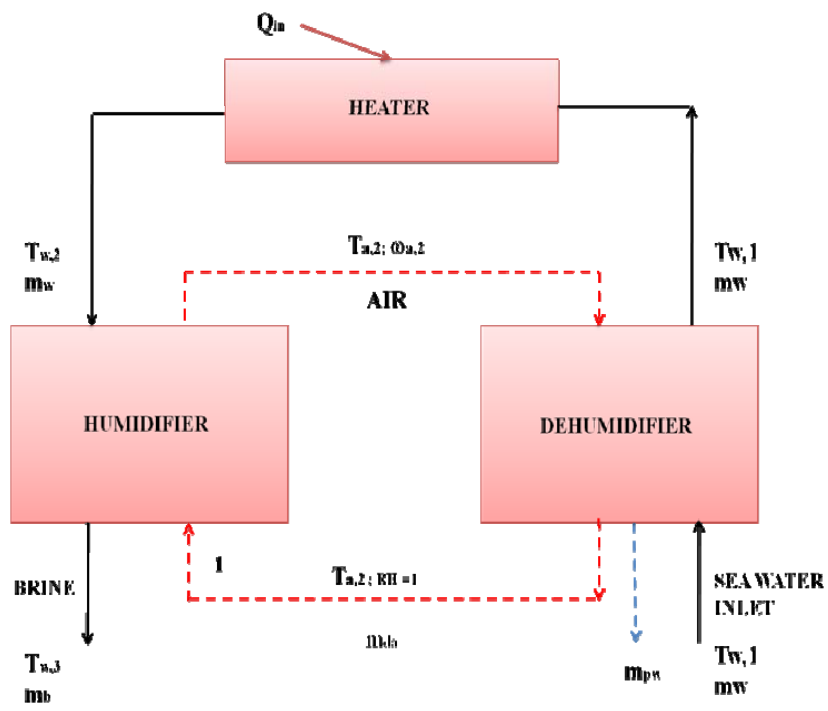

Fig. 5: Physical model of water heated CAOW HDH cycle

'For our analysis Closed Air Open Water (CAOW) cycle was selected. The boiling water humidifies the humidifier by making its high temperature water and air to flow on it. This procedure on the psychometric outline is spoken to by the line 1-2 (Fig. 5). Utilizing sea water as coolant, the humidified air is sent to the dehumidifier in a small heat exchanger where the humidified air cooled to a lower temperature. The seawater gets preheated all the while and is additionally warmed in a radiator'

\subsection{Performance parameters of the HDH system}

The following factors are considered as the performance parameters of the HDH system:

i. Gained Output Ratio (GOR.

ii. Productivity of the system

iii. Recovery Ratio (RR)

\subsubsection{Gained Output Ratio (GOR)}

This is the ratio of the latent heat of evaporation of the resulting water to the total heat introduced into the cycle.

$$
G O R=\frac{m_{p w} \cdot h_{f g}}{Q_{i n}}
$$

The structure of HDH system is mainly affected by the heat recovery measurement which acts as an important parameter in disturbing the efficient production of water. This is an important performance parameter of enthusiasm for $\mathrm{HDH}$ and is basically the same as the performance indicator (PR), characterized for media MED and MSF [16]. For steam-oriented desalination systems PR is roughly equivalent to GOR

Fig. 4: Physical model of Heater 


$$
\begin{aligned}
G O R & =\frac{m_{p w} \cdot h_{f g}}{m_{s} \cdot \Delta h_{s}} \\
\approx & \frac{m_{p w}}{m_{s}} \\
& =\mathrm{PR}
\end{aligned}
$$

The proportion of latent heat $\left(\mathrm{h}_{\mathrm{fg}}\right)$ to specific energy consumption acts as a vital element in characterizing the Gained Output Ratio (GOR). By determining the partial pressure of the water vapor in the dehumidifier, the latent heat for the above conditions are ascertained.

\subsubsection{Productivity and Recovery Ratio of the system}

Productivity is the measure of quantity of water delivered per unit time of activity; it is the main criteria to determine the system capability to produce the fresh water while Recovery Ratio (RR) is the extent of the amount of water conveyed per $\mathrm{kg}$ of feed.

$$
R R=\frac{m_{p w}}{m_{s w}}
$$

\subsection{Thermodynamic Formulation $[17,18]$}

\section{i. Governing equations for humidifier}

Mass balance equation

$$
m_{b}=m_{s w}-m_{d a}\left(\omega_{a, 2}-\omega_{a, 1}\right)
$$

Energy Balance equation

$$
m_{b} h_{b}-m_{s w} h_{s w, 3}=m_{d a}\left(h_{a, 1}-h_{a, 2}\right)
$$

\section{ii. Governing equations for dehumidifier}

Mass balance equation

$$
m_{p w}=m_{d a}\left(\omega_{a, 2}-\omega_{a, 1}\right)
$$

Energy balance equation

$$
m_{s w}\left(h_{s w, 2}-h_{s w, 1}\right)+m_{p w} h_{p w}=m_{d a}\left(h_{a, 2}-h_{a, 1}\right)
$$

iii. Governing equations for heater

$$
Q_{i n}=m_{s w}\left(h_{s w, 3}-h_{s w, 2}\right)
$$

iv. Equations to calculate the properties of air
Regression analysis has been done to obtain an equation to calculate the properties of air.

Specific heat at constant pressure

$C_{p}=2 E-08 T^{4}-6 E-06 T^{3}+0.0009 T^{2}-0.016 \mathrm{~T}+1004.9$

v. Partial pressure of water vapor present in the air

$\mathrm{p}_{\mathrm{v}}=1 \mathrm{E}-06 \mathrm{~T}^{4}-3 \mathrm{E}-05 \mathrm{~T}^{3}+0.0036 \mathrm{~T}^{2}+0.0168 \mathrm{~T}+0.67$

vii. Equations to calculate the properties of sea water and moist air [17]

Specific heat of sea water

$c_{p s w}=A+B T+C T^{2}+D T^{3}$

Where

$$
\begin{aligned}
& A=5.328-9.76 * 10^{-2} S+4.04 * 10^{-4} S^{2} \\
& B=-6.913 * 10^{-3}+7.351 * 10^{-4} S-3.15^{*} 10^{-6} S^{2} \\
& C=9.6 * 10^{-6}-1.927 * 10^{-6} S+8.23 * 10^{-9} S^{2} \\
& D=2.5 * 10^{-9}+1.666 * 10^{-9} S-7.125 * 10^{-12} S^{2}
\end{aligned}
$$

Enthalpy of moist air

$$
h=h_{a}+\omega h_{v}
$$

$$
h=c_{p a} T+\omega(2501+1.9 T) \mathrm{Kj} / \mathrm{Kgk}
$$

\subsection{Validation of current model with previous study}

In order to verify the results of current model, the system performance (GOR) is validated with the experimental results obtained from Zubair et al. [1]. It is discovered that the greatest deviation between the proposed model and alluded framework is around $16 \%$. Since the present model is meant to decrease the monetary expense of the HDH desalination framework, external means like heat pump, desiccant layers, heat exchangers etc. are not utilized that affects the efficiency of the system to a larger extent. Therefore, the reliability of the proposed water heated COAW HDH desalination system is verified. 


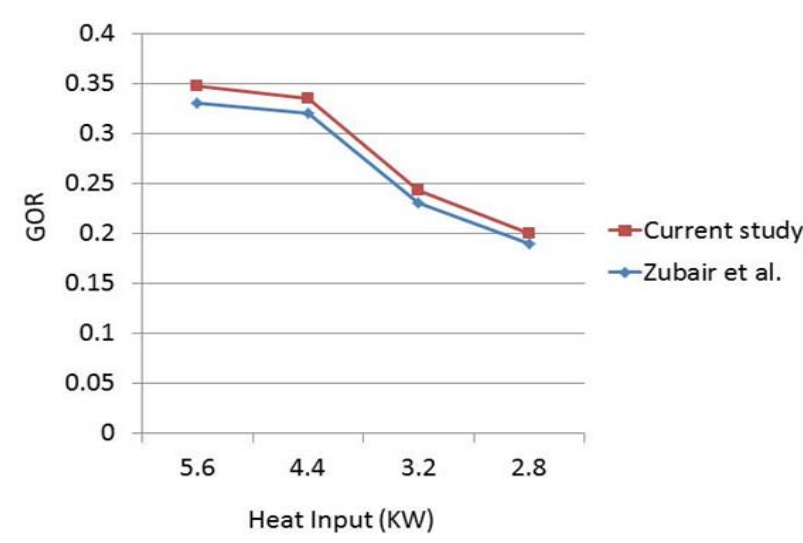

Fig.6: Validation with experimental study

\section{Results and discussion}

To break down the effect of mass flow rate of air on Gained Output Ratio (GOR) at various temperatures of inlet air, a set of value is executed in the ' $\mathrm{C}$ ' program. Fig.7 shows that the optimum efficiency of GOR and mass flow rate of air, obtained at $28^{\circ} \mathrm{C}$ which is around 0.015 and $28 \mathrm{Kg} / \mathrm{min}$ respectively. It also infers that higher efficiency can be obtained at minimum temperature $\left(<28^{0} \mathrm{C}\right)$ itself instead of using higher temperatures. The ascent in mass stream rate of air and decline in the temperature of channel air prompted a high GOR.

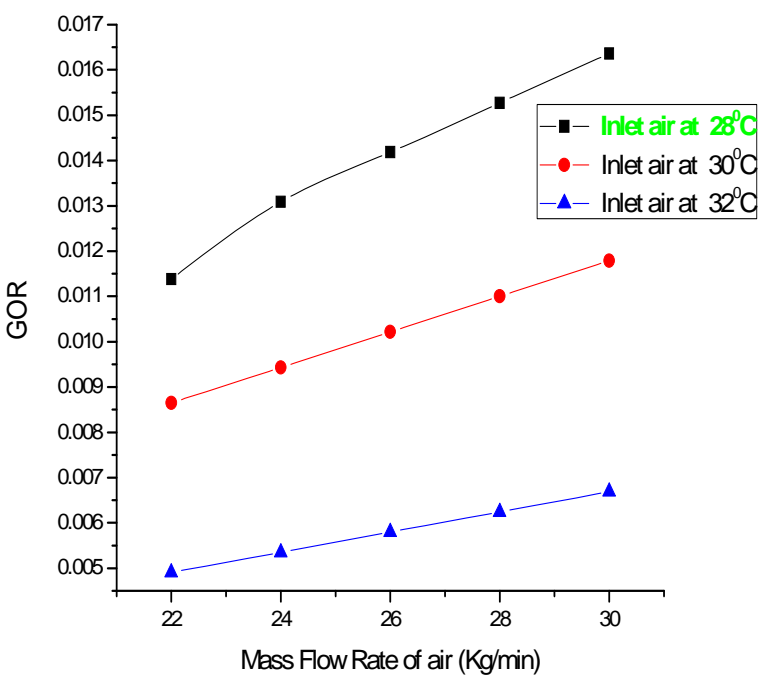

Fig.7: Impact of mass flow rate of air on Gained Output Ratio

Fig. 8 shows the significant yield of fresh water production on mass flow rate of air at peculiar heat inputs ranging from $15 \mathrm{Kw}$ to $25 \mathrm{Kw}$. It is observed that more fresh water output of $0.32 \mathrm{Kg} / \mathrm{min}$ is obtained at a heat load of $15 \mathrm{Kw}$ and $30 \mathrm{Kg} / \mathrm{min}$ mass flow rate. It proves that high desalination rate can be achieved at low heat inputs and high mass flow rate of air which also reveals that increasing stream flow rate raises the distillate flow rate. For the purpose of validation with Zubair et al., a small range of heat load from 1 to $6 \mathrm{KW}$ is given as input where it contributed a maximum GOR of 0.349 .

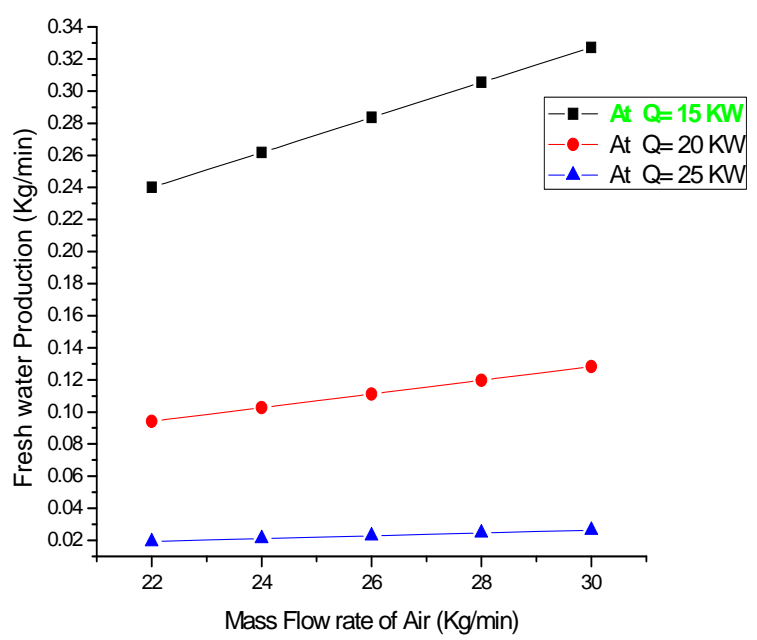

Fig.8: Significance of mass flow rate of air on Fresh water production

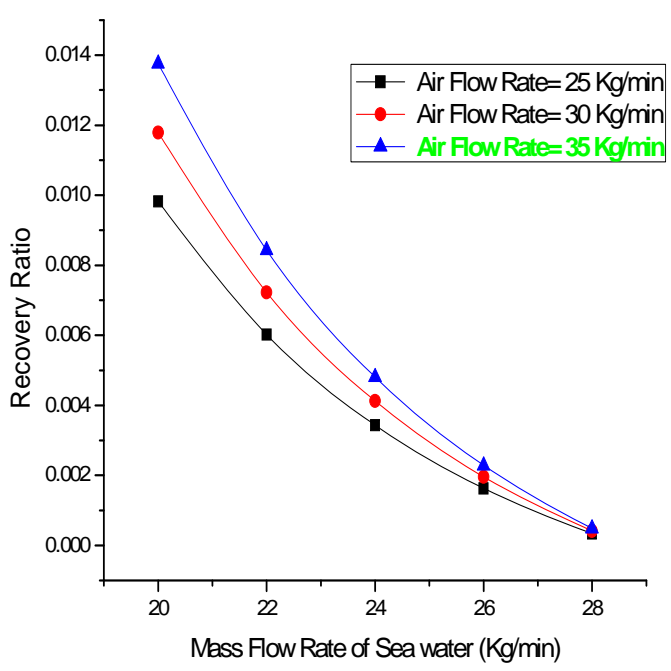

Fig.9: Effect of mass flow rate of sea water on Recovery Ratio and air flow rate

High Recovery Ratio is needed for obtaining a cheaper and more economic desalination system. The impingement of Recovery Ratio on the mass flow rate of 
sea water at different air flow rates is indicated in Fig.9. It interprets that Recovery Ratio decreases on increasing the flow rate of seawater. Since the concentration of water vapor in air and water-air layer is high, the Recovery Ratio reduced while mass flow rate of air is increased. On the other hand, with high air flow rate of $35 \mathrm{Kg} / \mathrm{min}$ an excellent Recovery Ratio of 0.014 is attained at a less mass flow rate of sea water of 20 $\mathrm{Kg} / \mathrm{min}$.

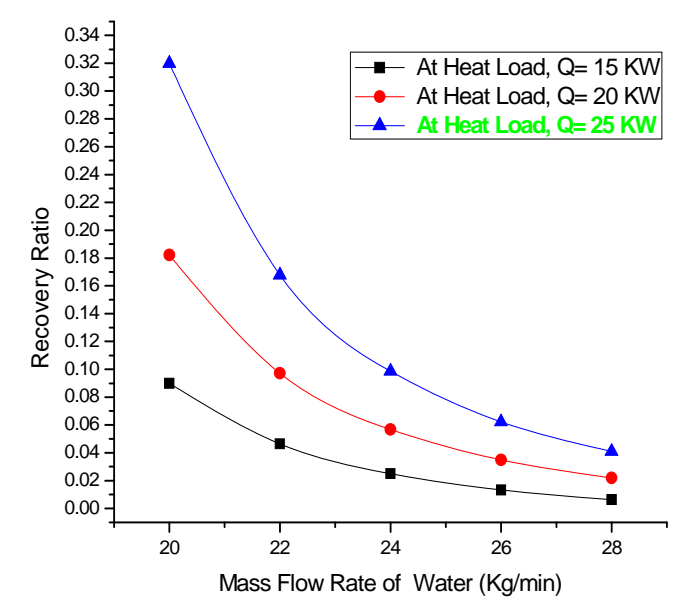

Fig.10: Effect of mass flow rate of water on Recovery Ratio and Heat loads

Fig.10 shows the maximum yield of the recovery factor for mass flow of water at various thermal loads. He confirms that with a high thermal load of $25 \mathrm{~kW}$ can lead to a recovery ratio of 0.33 at a very low mass flow rate of $20 \mathrm{~kg} / \mathrm{min}$. The capacity to vaporize fresh water from saline water is dependent on various heat sources like Photovoltaic panels, solar thermal etc, are not utilized which affected the RR of the system to decrease constantly. This also justifies the reduction in the recovery factor when the mass flow of water increases. Increasing the heat load of the heater with a constant mass flow of sea water to the system will increase the efficiency of air humidification, which will lead to high freshwater productivity. Therefore, because of the high heat load, there is an increase in the amount of water evaporated per kilogram of input water, since the recovery factor increases with increasing heat input.

\section{Conclusion}

The theoretical study carried out by applying thermodynamic principles on the $\mathrm{HDH}$ system reveals that:

- The increased mass air flow increases the GOR efficiency and the production of fresh water at a reduced inlet temperature and lower heat load of the proposed Humidification dehumidification system.

- Increasing the consumption of sea water reduces the Recovery Ratio of the HDH system with increasing airflow and heat load.

- The economic cost of the proposed system is very low as no external sources are used as such the performance of the system is also in a lower range.

\section{Acknowledgements}

The creators of current work might want to recognize with thankfulness, Universiti Teknologi PETRONAS (UTP) for their offices and liberal help to effectively finish this project. Special thanks to Mr. Sundarajoo Thulasiraman, Mr. Namdev Patil and Mr. Junaid Muhammad for supporting us in analysis work.

\section{References}

1) K Syed M. Zubair, Mohamed A. Antar, Samih M. Elmutasim, Dahiru U. Lawa, "Performance evaluation of humidification-dehumidification (HDH) desalination systems with and without heat recovery options: An experimental and theoretical investigation", Desalination, 436, 161-175 (2018).

2) Dahiru Lawal, Mohammed Antar, Atia Khalifa, Syed Zubair, Fahad Al-Sulaiman, "Humidification dehumidification desalination system operated by a heat pump", Energy Conversion and Management, Volume 161, 128-140 (2018).

3) Soufari, S. M., M. Zamen, and M. Amidpour, "Performance optimization of the humidification-dehumidification desalination process using mathematical programming”, Desalination, 237.1, 305-317 (2009).

4) Gang wu, Cagri Kutlu, Hongfei Zheng, Yuehong Su, Dandan Cui, "A study on the maximum gained output ratio of single-effect solar humidification-dehumidification desalination", Solar Energy, Volume 157, 1-9 (2017).

5) W.F. He, L.N. Xu, D. Han, L.Gao, W.H. Pu, "Thermodynamic investigation of waste heat driven desalination unit based on humidification dehumidification (HDH) processes", Applied Thermal Engineering, Volume 100, 315-324 (2016).

6) W.F. He, D. Han, C. Yue, W.H. Pu, "A Parametric study of a humidification dehumidification (HDH) desalination system using low grade heat sources", Energy Conversion and Management, Volume 105, 929-937 (2015).

7) Ahmed .M.A., Syed M. Zubair, Abido, Haitham M., 
"An innovative closed-air closed-desiccant $\mathrm{HDH}$ system to extract water from air: A case for zero-brine discharge system", Desalination, Volume 445, 236-248 (2018).

8) Nabil A.S, Farooq R. Siddiqui, Mohammed F. Addas, "Development of an active solar humidification-dehumidification desalination system integrated with geothermal energy", Energy Conversion and Management, Volume 126, 608-621(2016).

9) Mohammad Behshad Shafii, Hamed Jafargholi, Meysam Faegh, "Experimental investigation of heat recovery in a humidification-dehumidification desalination system via a heat pump", Desalination, Volume 437, 81-88 (2018).

10) W.F.He, L.N. Xu, D. Han, "Parametric analysis of an air-heated humidification-dehumidification (HDH) desalination system with waste heat recovery", Volume 398, 30-38 (2016).

11) Saeed Dehghani, Abhijit Date, Aliakbar Akbarzadeh, "Performance analysis of a heat pump driven humidification-dehumidification desalination system", Desalination, Volume 445, 95-104 (2018).

12)Hadi Rostamzadeh, Amin Shekari Namin, Hadi Ghaebi, Majid Amidpour, "Performance assessment and optimization of a humidification dehumidification (HDH) system driven by absorption-compression heat pump cycle", Desalination, Volume 447, 84-101 (2018).

13)Jun-hong Wang, Nai-yun Gao, Yang Deng, Yong-li, "Solar power-driven humidification-dehumidification process for desalination of brackish water", Desalination, Volume 305, 17-23 (2012).

14) Shahzad Muhammad Wakil, Thu Kyaw, Saha Bidyut Baran, Ng Kim Choon, "An emerging hybrid multi-effect adsorption desalination system", Evergreen.1 (2), 30-36 (2014).

15)Luther R.Wilhelm, "Numerical calculation of physical properties of air in S.I units", Transactions of the ASAE (1976).

16) Adel and M. Fatouh, "Experimental and Numerical Investigation of Humidification/Dehumidification Solar Water Desalination Systems", Desalination, 247, 594-609 (2009).

17) Sharqawy, Mostafa H., John H. Lienhard V and Syed M. Zubair, "The thermo physical properties of seawater: A review of existing correlations and data", Desalination and Water Treatment, 16, 354-380 (2010).
18) A.E.Kabeel, Mofreh H. Hamed, Z.M. Omara, S.W. Sharshir, "Experimental study of a humidification-dehumidification solar technique by natural and forced air circulation", Energy, 68, 218-228 (2014).

19) Farsad and Behzadma, "Numerical analysis of an integrated desalination unit using humidification-dehumidification and subsurface condensation processes", Desalination, Vol. 433, 172-185 (2018).

20) Cemil, Yamali and Ismail Solmus, "A solar desalination system using HDH process, experimental study and comparison with the theoretical results", Desalination, 220, 538-551 (2008).

21) Yuan and Guofeng, "Experimental study of a solar desalination system based on humidification-dehumidification process", Desalination, 277, 92-98 (2011).

22) Narayan and G. Prakash, "Thermodynamic analysis of humidification dehumidification desalination cycles", Desalination and Water Treatment, 16, 339-353 (2010).

23) Efafz. Mahdizade and Mehran Ameri, "Thermodynamic investigations of a semi-open air humidification dehumidification desalination system using air and water heaters", Desalination, Volume 428, 182-198 (2018).

24) Xiaoni Qi, Yongqi Liu, Qianjian Guo, Jie yu, Shanshan $\mathrm{Yu}$, "Performance prediction of seawater shower cooling towers", Energy, Volume 97, 435-443 (2016).

25) A.S. Abdullah, F.A. Essa, Z.M. Omara, M.A. Bek, "Performance evaluation of a humidification-dehumidification unit integrated with wick solar stills under different operating conditions", Desalination, Volume 441, 52-61 (2018).

26) Saeed Dehghani, Abhijit Date, Aliakbar Akbarzadeh, "Humidification-dehumidification desalination cycle", Emerging Technologies for Sustainable Desalination Handbook, pp.227-254 (2018).

27) Younes ghalavand, Amir Rahimi, Mohammad Sadegh Hatamipour, "Mathematical modelling for humidifier performance in a compression desalination system: Insulation effects", 
Desalination, Volume 433, 48-55 (2018).

28) Bruno campos, Andrea costa, Katia Figueiredo, Esly junior, "Performance comparison of different mathematical models in the simulation of a solar desalination by humidification-dehumidification", Desaliantion, Volume 437, 184-194 (2018).

29) Mostafa Sharqawy, Mohamed Antar, Syed Zubair, Abubaker Elbashir, "Optimum thermal design of humidification dehumidification desalination systems", Volume 349, 10-21 (2014).

30) Karim Chehayeb, Prakash Narayan, Syed Zubair, John Lienhard, "Use of multiple extractions and injections to thermodynamically balance the humidification dehumidification desalination system", International Journal of Heat and Mass Transfer, Volume 68, 422-434 (2014).

31) Nabil Elminshawy, Farooq Siddiqui, Mohammad Addas, "Experimental and analytical study on productivity augmentation of a novel solar humidification-dehumidification (HDH) system", Desalination, Volume 365, 36-45 (2015).

32) Mohamed Mahmoud, Taha Farrag, Wael Mohamed, "Experimental and theoretical model for water desalination by humidification-dehumidification (HDH)", Procedia Environmental Science, Volume 17, 503-512 (2013).

33) Adewale giwa, Nawshad Akther, Amna Al Housani, Sabeera Haris, Shadi wajih Hasan, "Recent advances in humidification dehumidification (HDH) desalination processes: Improved designs and productivity", Renewable and Sustainable Energy Reviews, Volume 57, 929-944 (2016).

34) Ang Li, Azhar Bin Ismail, Kyaw Thu, Muhammad Wakil Shahzad, Kim Choong Ng, Bidyut Baran Saha, "Formulation of Water Equilibrium Uptakes on Silica Gel and Ferroaluminophosphate Zeolite for Adsorption Cooling and Desalination Applications", Evergreen, Volume 01, Issue 02, pp. 37-45 (2014).

\section{Nomenclature}

$\mathrm{T}_{\mathrm{a}, 1} \quad$ Temperature of dehumidified air entering to the humidifier $\left({ }^{\circ} \mathrm{c}\right)$

$\mathrm{T}_{\mathrm{a}, 2} \quad$ Temperature of humidified air at the outlet of the humidifier $\left({ }^{\circ} \mathrm{c}\right)$

$\mathrm{T}_{\mathrm{sw}, 1} \quad$ Temperature of sea water entering to the dehumidifier $\left({ }^{\circ} \mathrm{c}\right)$

$\mathrm{T}_{\mathrm{sw}, 2} \quad$ Temperature of sea water leaving the dehumidifier $\left({ }^{\circ} \mathrm{c}\right)$

$\mathrm{T}_{\mathrm{sw}, 3} \quad$ Temperature of sea water entering to the humidifier $\left({ }^{\circ} \mathrm{c}\right)$

$\mathrm{T}_{\mathrm{b}} \quad$ Temperature of brine coming out of the humidifier $\left({ }^{\circ} \mathrm{c}\right)$

$\mathrm{p}_{\mathrm{v}} \quad$ Saturation pressure of water vapor present in the air $\left(\mathrm{KN} \mathrm{m}^{-2}\right)$

$\mathrm{p}_{\mathrm{t}}$

Atmospheric pressure $\left(\mathrm{KN} / \mathrm{m}^{2}\right)$

$\mathrm{C}_{\mathrm{psw}} \quad$ Specific heat of sea water $(\mathrm{KJ} / \mathrm{kg} . \mathrm{K})$

$\mathrm{m}_{\mathrm{sw}} \quad$ Mass flow rate of sea water $(\mathrm{kg} / \mathrm{min})$

$\mathrm{m}_{\mathrm{da}} \quad$ Mass flow rate of dry air $(\mathrm{kg} / \mathrm{min})$

$\mathrm{m}_{\mathrm{b}} \quad$ Mass of brine $(\mathrm{Kg} / \mathrm{min})$

$\omega_{\mathrm{a}, 1} \quad$ Humidity ratio of the inlet air

$\omega_{\mathrm{a}, 2} \quad$ Humidity ratio of the outlet air

$\phi_{1} \quad$ Relative humidity of the inlet air

S Salinity of sea water ( $\mathrm{mg} / \mathrm{l})$

$\mathrm{h}_{\mathrm{a}} \quad$ Enthalpy of air $(\mathrm{KJ} / \mathrm{Kg})$

CAOW Closed Air Open Water Cycle

GOR Gained Output Ratio

RR Recovery Ratio

$\mathrm{HDH}$ Humidification Dehumidification 